\title{
An Investigation on Weldability of Flared D9 Tube to Cylindrical SS316L (N) Plug Using Electro-Magnetic Compression Welding
}

\author{
Satendra Kumar ${ }^{*}$, G. K. Dey², Archana Sharma1,2 \\ ${ }^{1}$ Homi Bhabha National Institute, Bhabha Atomic Research Center, Mumbai, India \\ ${ }^{2}$ Bhabha Atomic Research Center, Mumbai, India \\ Email: *satendra@barc.gov.in, gkdey@barc.gov.in, arsharma@barc.gov.in
}

How to cite this paper: Kumar, S., Dey, G.K. and Sharma, A. (2019) An Investigation on Weldability of Flared D9 Tube to Cylindrical SS316L (N) Plug Using Electro-Magnetic Compression Welding. Open Access Library Journal, 6: e5465. https://doi.org/10.4236/oalib.1105465

Received: May 10, 2019

Accepted: May 24, 2019

Published: May 27, 2019

Copyright $\odot 2019$ by author(s) and Open Access Library Inc.

This work is licensed under the Creative Commons Attribution International License (CC BY 4.0).

http://creativecommons.org/licenses/by/4.0/

\section{(c) (i) Open Access}

\begin{abstract}
Geometry configurations of joining partners (similar/dissimilar metals) are important to achieve effective and smooth joint in electromagnetic (EM) compression welding. Accordingly, design of welding tool (multi-turn coil) becomes challenging [1]. EM welding of flared D9 flyer tube to SS316 L (N) straight cylindrical plug has been performed under a discharge voltage of 15 - $17 \mathrm{kV}$ with coil current $230-250 \mathrm{kA}$ at around $15.1 \mathrm{kHz}$ ringing frequency. A multi-turn coil having inner diameter as flared profile identical to the geometry of flyer tube was designed along with flared $\mathrm{Cu}$ (annealed) driver tube. Non-destructive tests (helium leak test and X-ray tomography) and destructive tests (sectional micrographs and micro hardness test) have been conducted on welded samples to verify the interface bond formation. The transition zone at weld interface exhibits severe plastic deformation due to strain hardening with an increased hardness of around $504 \mathrm{VHN}$ and a smooth wavy pattern of a maximum crest height of $40 \mu \mathrm{m}$. All the weld samples showed a leak rate of the order of $10^{-9} \mathrm{~m} \cdot \mathrm{bar} \cdot \mathrm{L} / \mathrm{s}$. The present exercise of geometry modification in driver and joining metals with customized coil geometry contributed to the favorable joining conditions in EM welding.
\end{abstract}

\section{Subject Areas}

Applied Physics, Electrochemistry, Metal Material

\section{Keywords}

Tube Flaring, Multi-Turn Coil, EM Welding, Interface Micrograph, Non-Destructive Tests, Destructive Tests 


\section{Introduction}

When it comes to welding of dissimilar combination of metals, the challenges are more prominent as huge differences exist in various physical properties like melting point, thermal conductivity, etc. [2]. So impact welding processes, like explosive welding (EXW) and electromagnetic welding (EMW) are few viable solutions over fusion based technologies. They belong to the category of solid state welding processes where joining is accomplished by a high-velocity impact occurring for a shorter process cycle duration, resulting in a true metallurgical bond over varying lengths [3]. Nevertheless, each of these processes has distinct advantages, difficulties and limited field of applications. The advantages related to such impact welding techniques are that no heat affected zones (HAZs) are created at the joining interface because of low heating, materials are not degraded after joining and clean surfaces formation occurs prior to welding as a consequence of the jet [4]. As compared to other conventional welding methods, this method leads to only a very low formation of brittle inter-metallic compounds. However, although this method has many advantages, very limited industrial applications have so far been achieved. In recent years, this technology has gained a lot of momentum. A lot of commercial and reactor applications are being tried globally.

In contrast to EXW, electromagnetic (EMW) welding is an easily controlled safe process preferably for the joining of similar/dissimilar high conductive metals for both sheets and tubular geometry configuration with weld lengths limited to centimeters. Comparatively the energy input in EM welding is very low which also constraints the thickness of the accelerated part. In EMW, a pulsed magnetic field gets generated in tool coil, as the stored capacitive energy discharges. The transient magnetic field induces eddy current on the outer plate/tube which in turn generates secondary magnetic field in opposite direction and a repulsive radial Lorentz force applies on the flyer part to accelerate and collide with stationary member inducing stresses beyond its yield stress to form a solid-state weld. The process results in strong, smooth and clean welded joints but coil geometry and life and optimization of other welding parameters are some critical issues in this technology [5].

EM welding of D9 tube to SS316L (N) plug has got direct reactor applications where smooth coolant flows as there is no volume change over weld length. So, to achieve a smooth and effective weld, a novel thought was to investigate experimentally the weldability of "flared profile" D9 flyer tube over "straight profile" SS316 L (N) plug using annealed $\mathrm{Cu}$ driver. The proposed geometry configuration has got its own advantages over tapered plug configuration (Figure 1) which has continuous reduction in volume over weld length. Process parameters like discharge current, taper angle of tool coil/D9 tube, axial placement of job and driver thickness were optimized. The characterization of weld quality is performed using nondestructive test (helium leak test and X-ray tomography) and destructive tests (sectional micrographs) to reveal interface bonding condition. 
(a)

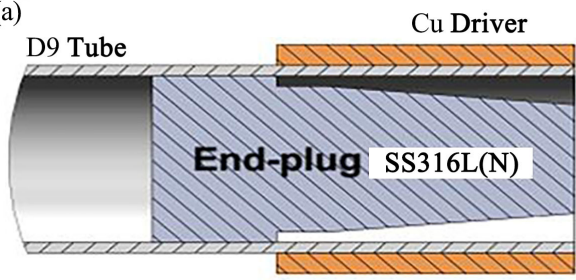

(b)

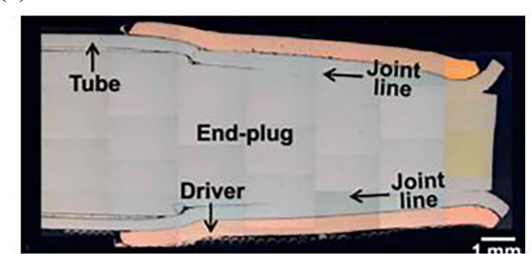

Figure 1. Schematic of driver-job pieces positioning with tapered plug configuration in EM welding (a) before welding (b) after welding.

\section{Experimental Methodology}

Alloy D9 steel is having a very low electrical conductivity (2\% IACS) and very high yield strength (800 MPa). Due to low electrical conductiveity, it is obvious that it cannot be driven directly over SS316L (N) plug for EM welding. Here, a conducting driver (annealed copper) of thickness twice the skin depth in copper at ringing frequency is employed to drive the flyer tube over stationary plug in EM welding. Copper driver absorbs all magnetic pressure generated in the vicinity of the tool coil and will drive D9 tube over SS316L (N) plug. As there is no gap between copper driver and D9 tube, they are not welded together during the process. Simultaneously, a customized multi-turn tool coil with high yield strength material having good electrical conductivity is designed. For this purpose $\mathrm{Be}-\mathrm{Cu}$ material $(2 \% \mathrm{Be})$ is chosen. It is having yield strength in the range of $800 \mathrm{MPa}$ and conductivity around 30\% IACS (18 MS/m).

Figure 2 shows photograph of flared profile D9 tube and straight profile cylindrical plug as well as flared annealed copper driver on D9 tube. Detailed dimensions of coil-driver-job pieces geometry combination are mentioned in Table 1.

All the experimental tests were conducted using $70 \mathrm{~kJ}$ EM welding setup. Table 2 provides the capacitor bank specifications. A customized multi-turn coil (helical disc based) with 06 discs having 05 effective turns of thickness $4 \mathrm{~mm}$ each is fabricated. A sufficient magnetic pressure (B field) is a necessary condition but not sufficient for leak proof EM weld joint. Concentric and mechanically arresting fixture is an essential part of EM welding; improper fixture leads to no welding and leaking weld joint. A perfect fixture should firstly make the job-piece combination perfectly concentric inside coil ID and secondly it should arrest any axial movement possible during EM welding process. An integrated EM fixture (fixture on the coil itself) has been designed to hold on $\mathrm{Cu}$ driver-D9 SS flyer tube-SS316L (N) plug combination axially. It is represented in Figure 3(a) and placement of job-piece inside coil ID is shown in Figure 3(b). A lot of experimental trials were conducted to arrive least possible value of coil current (230 kA) to produce desired EM weld joint.

Parameters like applied voltage, coil current and ringing frequency were recorded during EM welding tests of flared D9 tube over SS316L (N) cylindrical plug. As there is no international standard available for EM weld qualification, many researchers prefer various destructive or non-destructive inspection tech- 
niques for weld characterization and evaluation. In present case, helium leak test and X-ray tomography were performed on all weld samples. Samples providing HLT in the range of $10^{-9} \mathrm{~m} \cdot \mathrm{bar} \cdot \mathrm{L} / \mathrm{s}$ leak rate are studied for sectional micrographs to evaluate weld length and weld strength. Micro hardness test was conducted to analyze hardness profiles at weld interface. Line scan using FAG-SEM was done across weld interface to check elemental migration if any.

Table 1. Dimensions of driver-job piece configuration.

\begin{tabular}{cccccc}
\hline & $\begin{array}{c}\text { Outer diameter } \\
(\mathrm{mm})\end{array}$ & $\begin{array}{c}\text { Inner diameter } \\
(\mathrm{mm})\end{array}$ & $\begin{array}{c}\text { Thickness } \\
(\mathrm{mm})\end{array}$ & $\begin{array}{c}\text { Flared length } \\
(\mathrm{mm})\end{array}$ & $\begin{array}{c}\text { Straight length } \\
(\mathrm{mm})\end{array}$ \\
\hline $\begin{array}{c}\text { Alloy D9 } \\
\text { steel tube }\end{array}$ & $21.4-26.17$ & $20-24.77$ & 0.7 & 17 & 23 \\
$\begin{array}{c}\text { SS316L (N) } \\
\text { plug }\end{array}$ & 19.95 & - & - & - & 40 \\
$\begin{array}{c}\text { Annealed } \\
\text { Cu driver }\end{array}$ & $22.4-27.17$ & $21.4-26.17$ & 0.5 & 17 & 23 \\
$\begin{array}{c}\text { Be-Cu coil } \\
(2 \% \text { Be })\end{array}$ & 200 & $23-27.77$ & - & - & - \\
\hline
\end{tabular}

Table 2. Technical specifications of capacitor bank and machine setup.

\begin{tabular}{cccccc}
\hline $\begin{array}{c}\text { Maximum } \\
\text { energy }\end{array}$ & $\begin{array}{c}\text { Maximum } \\
\text { operating voltage }\end{array}$ & Capacitance & $\begin{array}{c}\text { Short circuit } \\
\text { frequency }\end{array}$ & $\begin{array}{c}\text { Operating } \\
\text { Frequency }\end{array}$ & $\begin{array}{c}\text { Inductance of } \\
\text { multi-turn coil }\end{array}$ \\
\hline $70 \mathrm{~kJ}$ & $25 \mathrm{kV}$ & $224 \mu \mathrm{F}\left(04^{\star} 56\right)$ & $25 \mathrm{kHz}$ & $15.1 \mathrm{kHz}$ & $150 \mathrm{nH}$ \\
\hline
\end{tabular}
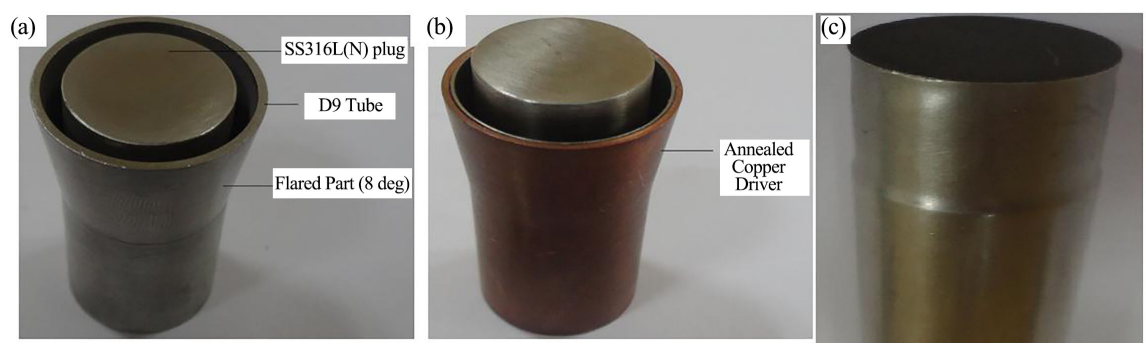

Figure 2. Schematic of driver-job pieces geometry configuration (a) flared profile D9 and straight SS316L (N) plug (b) copper driver enveloping job pieces.
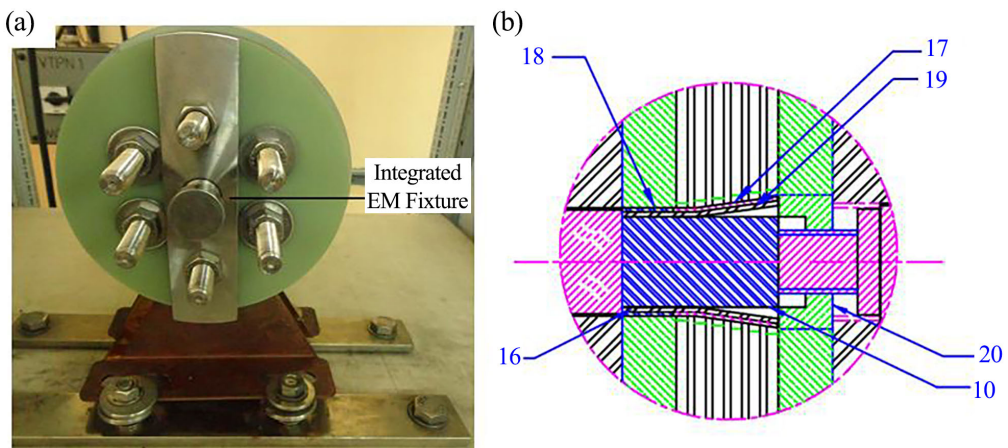

Figure 3. EM welding coil system (a) with integrated fixture (b) $2 \mathrm{D}$ cross-sectional view of coil-driver-job pieces positioning. 


\section{Results and Discussion}

When capacitive energy is discharged into inductive coil an exponentially decaying sinusoidal current is generated in the coil. Figure 4 shows typical current in electromagnetic coil with peak value of $250 \mathrm{kA}$. Ten consecutive EM welding experiments of flared D9 tube to SS316L (N) cylindrical plug were conducted with coil current ranging from $233 \mathrm{kA}-250 \mathrm{kA}$ at around $15.1 \mathrm{kHz}$ ringing frequency. Photograph of weld samples after removing copper driver by $\mathrm{HNO}_{3}$ (nitric acid) are shown in Figure 5.

\subsection{Optimization of Process Parameters and Weld Quality}

Helium leak test was performed on all weld samples and leak rate in the range of $3.4 \times 10^{-9}-1 \times 10^{-9} \mathrm{~m} \cdot \mathrm{bar} \cdot \mathrm{L} / \mathrm{s}$ were measured (Figure 6). This is the first and most important qualification criterion to access sound quality weld. Table 3 summarizes the results of experimental trials. The maximum peak current of 250 $\mathrm{kA}$ and the maximum magnetic field of $40 \mathrm{~T}$ was measured at a charging voltage of $16.8 \mathrm{kV}$ for ringing frequency of $15.1 \mathrm{kHz}$ at bank energy of $31.6 \mathrm{~kJ}$. The minimum peak current of $233 \mathrm{kA}$ and magnetic field of $37.3 \mathrm{~T}$ was measured at a ringing frequency of $15.1 \mathrm{kHz}$ at bank energy of $27.6 \mathrm{~kJ}$ for weld sample no. 1 showing the leak rate of $3.4 \times 10^{-9} \mathrm{~m} \cdot \mathrm{bar} \cdot \mathrm{L} / \mathrm{s}$ (Figure 5). For welding trials, when coil current measured was below $233 \mathrm{kA}$, leak rate recorded for such weld samples was around $10^{-8} \mathrm{~m} \cdot \mathrm{bar} \cdot \mathrm{L} / \mathrm{s}$. It shows that below the optimum value of 233 $\mathrm{kA}$ coil current, quality of weld is poor. Above $250 \mathrm{kA}$ coil current although we get helium leak rate $<$ (less than) $10^{-10} \mathrm{~m} \cdot \mathrm{bar} \cdot \mathrm{L} / \mathrm{s}$ but there were melt pockets observed during optical micrograph analysis. From the experimental evaluation, it is revealed that coil current in the range of $(233-250 \mathrm{kA})$ is suitable for producing leak proof and metallurgically sound electromagnetic welds without melt pockets at interface. It is clearly established that higher the coil current from optimum value $(233 \mathrm{kA})$, the amplitude of the magnetic pressure is higher at high capacitive bank energy resulting in a better helium leak rate for the corresponding weld samples.

\subsection{Evaluation of Weld Length}

All Weld samples having leak rate in the range of $3 \times 10^{-9} \mathrm{~m} \cdot \mathrm{bar} \cdot \mathrm{L} / \mathrm{s}$ were subjected to X-ray tomography for identification of gross defects if any, axially and longitudinally. Figure 7 shows X-ray tomography images both axially and in slice form for sample no. 3. X-ray tomography shows a uniform joining in a length of $7 \mathrm{~mm}$ out of $15 \mathrm{~mm}$ under consideration. Upper and lower part of sample shows detectable openings which is expected. 3D volume images of vertical cut section along the length (outside to inside) shows a clear cut interface merging along the intended length (Figure 7(a)). 3D volume images across the length shows consistent circumference closing along the intended length. This NDT inspection showed no flaw in the chosen weld sample, in fact a good joining was observed. 
Table 3. Summary of experimental trials.

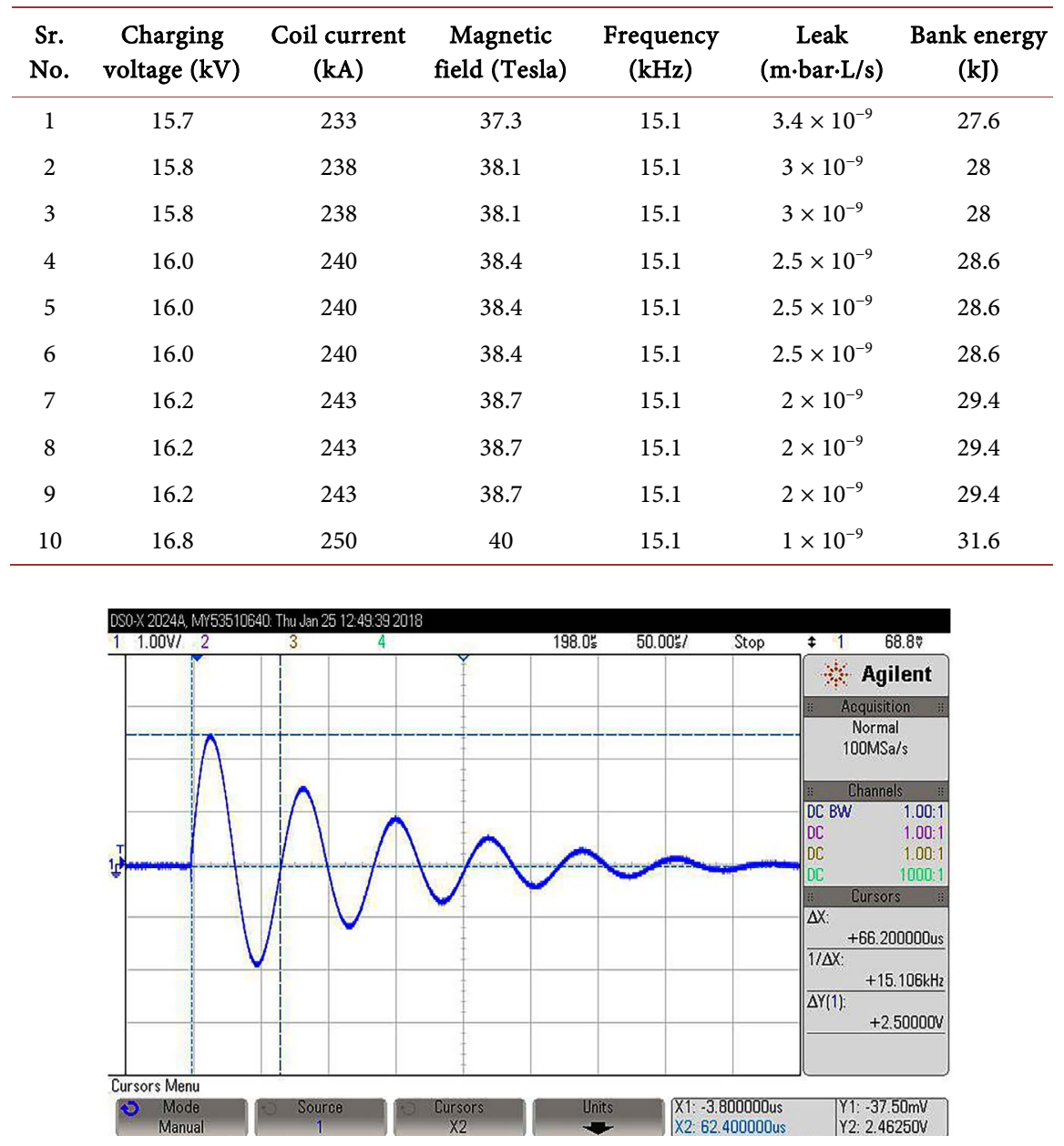

Figure 4. Exponentially decaying sinusoidal current recorded in the coil.

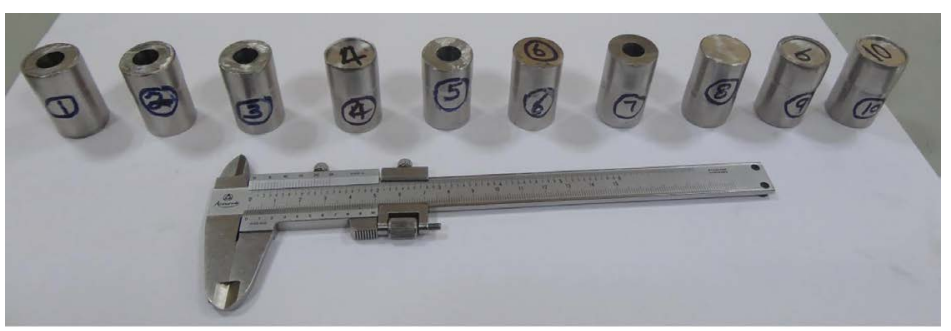

Figure 5. Weld samples of D9 tube to SS316L (N) after removing copper driver.

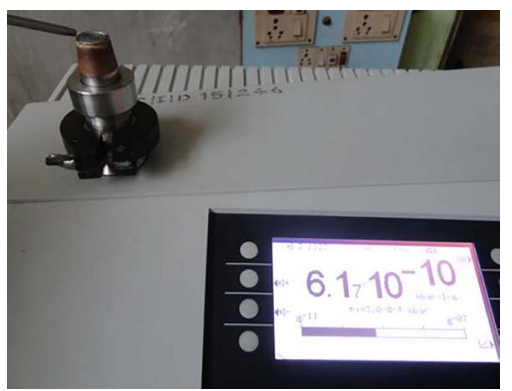

Figure 6. Helium leak test using MSLD. 
(a)
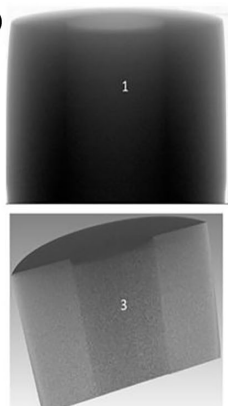
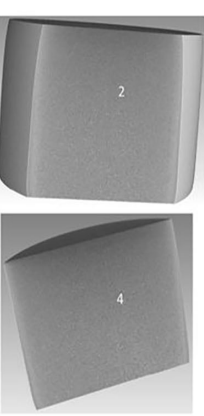

(b)

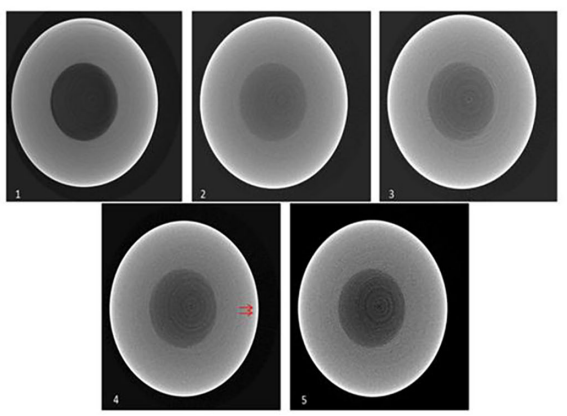

Figure 7. X ray Tomography (at 28 microns resolution) of weld sample no. 3 (a) 1: radiograph; $2,3,4: 3 \mathrm{D}$ reconstructed images cut vertically at various depths perpendicular to axial direction (b) 1 - 5: reconstructed slice images at various heights of the sample.

\subsection{Evaluation of Weld Interface}

EM welding and Explosive welding (EXW) are alike in process, only difference is the way of generating pressure. In EXW, pressure is generated by detonating the explosives while in EMW it is generated by electro-magnetic induction. It is quite natural to assume wavy characteristics at weld interface in EMW like EXW. Randomly selected EM welded sample no. 7 (leak rate-2 $\times 10^{-9}$ $\mathrm{m} \cdot \mathrm{bar} \cdot \mathrm{L} / \mathrm{s})$ was cut longitudinally to see the weld interface. Figure 8 shows interface micrographs along weld line at $100 \times$ resolution of a sample at $243 \mathrm{kA}$ current level. As evident, a distinct wavy interface of length $07 \mathrm{~mm}$ was observed at the weld interface. Figure 8(a) shows initiation of weld with successive rise in the crest height along the interface and finally falling of the crest height to a straight line in Figure 8(h). The crest height observed was in the range of 10 to $45 \mu \mathrm{m}$. Such wavy patterns have been widely reported in many EM and impact welding experimental studies. The mechanism of wave formation, theories and physics involved has not been discussed here. From the view of interface bonding in Figures 8(c)-(e) of optical micrograph, small rounded pores are observed at the weld line which can be recognized as interface melting due to severe plastic deformation causing grain instability and high strain hardening. For other regions along the bond, mechanical interlocking can be seen [6] [7].

\subsection{Line Scan across the Interface}

Table 4 shows element percentage in D9 and SS316L (N), we can see that there are only two materials which are present in D9 (Mo and Ti) but absent in SS316L (N). Line scan across weld interface of sample no. 7 was conducted using FAG-SEM to evaluate element transition (Ti and Mo if any) across the interface. Figure 9 shows FAG-SEM line scan at two different locations at weld interface. A scan run for $20 \mu \mathrm{m}$ length crossing interface shows that there is no/detectable transition of Ti and Mo from D9 to SS316LN side. Further techniques are being explored to detect transition elemental transition within $100 \mathrm{\eta m}$ range of weld interface. In EXW this transition is of the order of $1-2 \mu \mathrm{m}$ despite being all favorable conditions of pressure, temperature and time [8]. 
Table 4. Element composition in D9 steel and SS316L (N).

\begin{tabular}{ccc}
\hline & D9 Steel & SS316LN \\
\hline Element & Content (\%) & Content (\%) \\
\hline $\mathrm{C}$ & 0.04 & 0.03 \\
$\mathrm{Ni}$ & 15.5 & 14 \\
$\mathrm{Cr}$ & 14.04 & Nil \\
$\mathrm{Mo}$ & 2.2 & Nil \\
$\mathrm{Ti}$ & 0.26 & \\
$\mathrm{Si}$ & 0.61 & \\
$\mathrm{Mn}$ & 1.78 & \\
$\mathrm{~S}$ & $<0.02$ & \\
$\mathrm{P}$ & 0.07 & \\
$\mathrm{Al}$ & 0.06 & \\
$\mathrm{~B}$ & 0.0015 & \\
$\mathrm{~N}$ & 0.0037 & \\
\hline
\end{tabular}
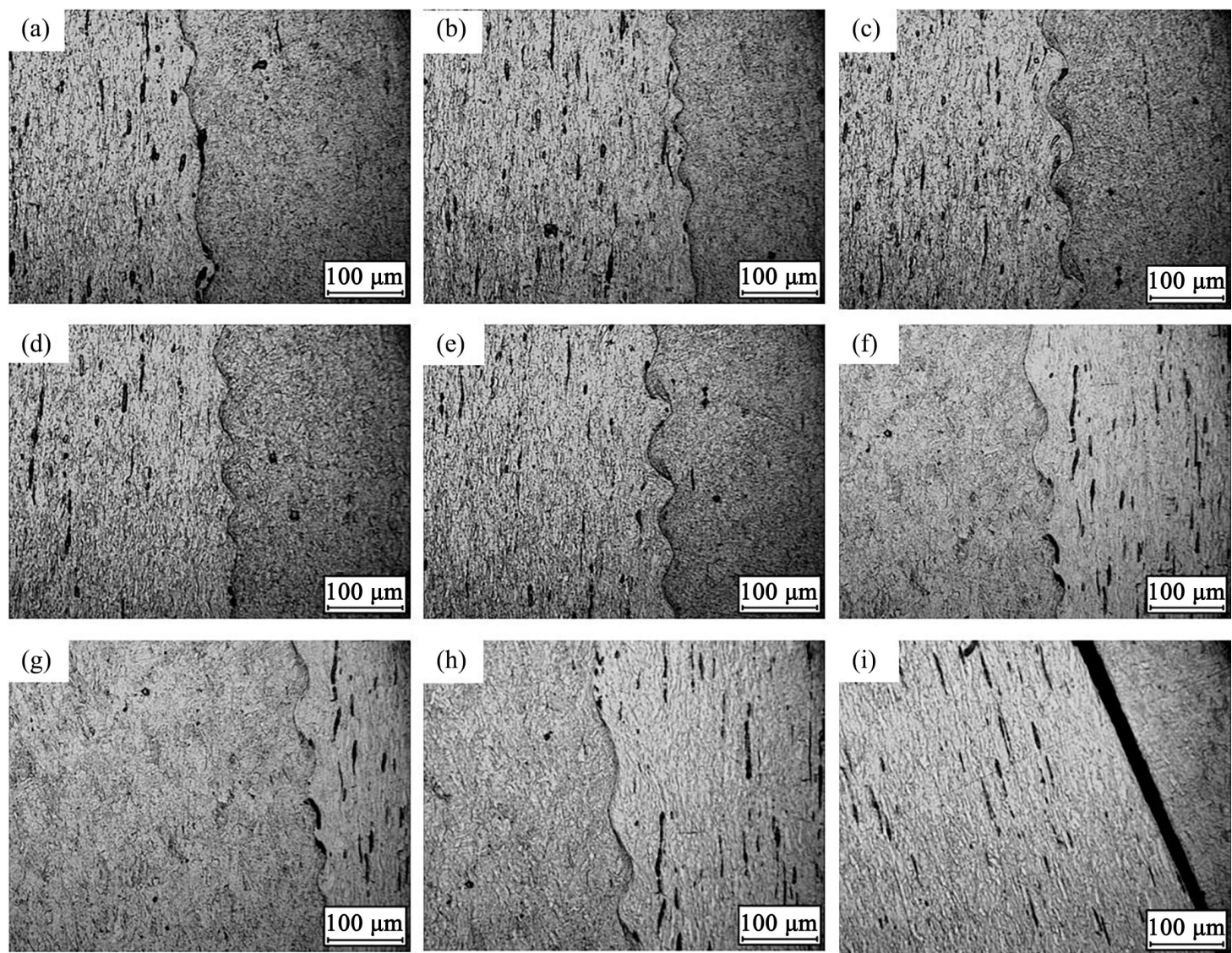

Figure 8. Optical micrograph at interface of electromagnetically welded D9-SS316L (N) sample. 


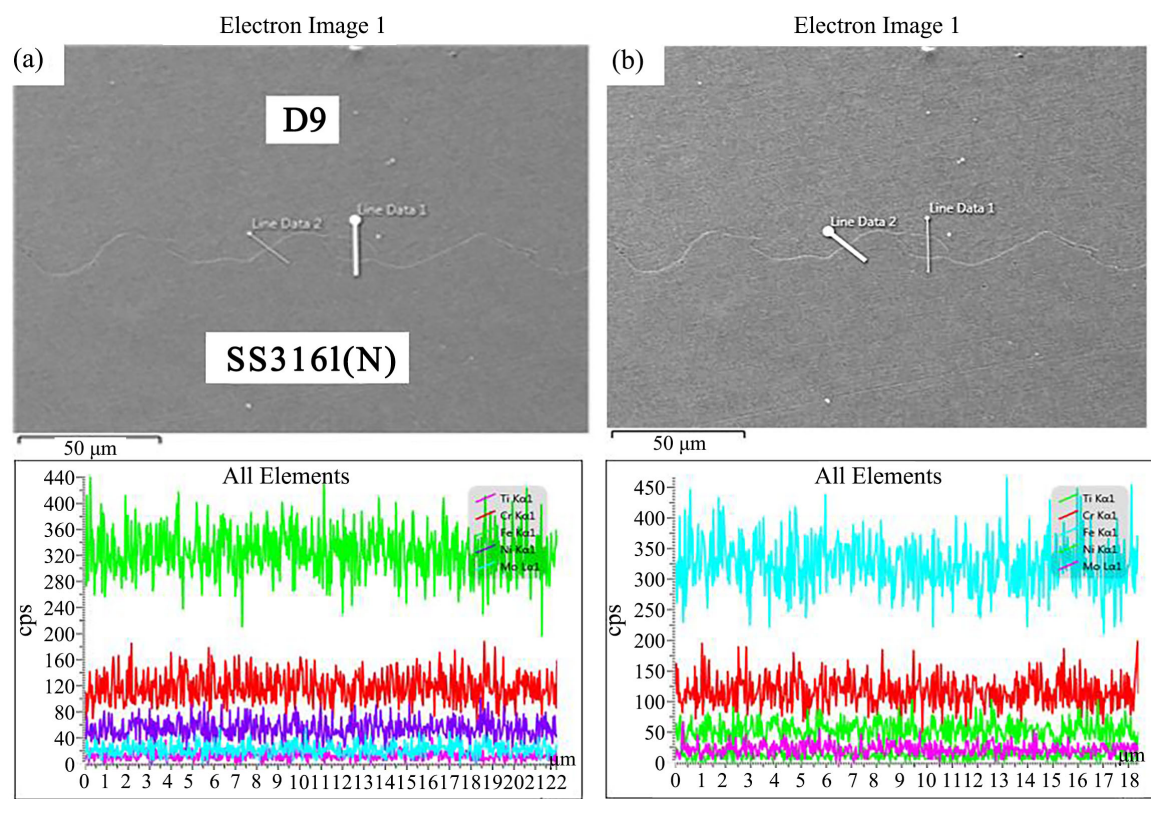

Figure 9. FAG-SEM line scan at two arbitrary locations to determine elementary migration across interface.

\subsection{Evaluation of Micro Hardness at Weld Interface}

Hardness measurement was done at weld interface to assess severity of plastic deformation around weld interface. A sufficiently large zone of the order of $0.275 \mathrm{~mm}$ was scanned for hardness variation. As expected peak hardness of 504 VHN was measured near the interface of D9/SS316L (N) electromagnetically welded joint. This is because of severe plastic deformation at this mid interface point. Around this mid interface point hardness was decreasing on both sides. Figure 10 shows hardness variation at weld interface in a range of $275 \mu \mathrm{m}$. Out of $275 \mu \mathrm{m}$, hardness change was observed in $175 \mu \mathrm{m}$. Hardness variation of interface confirms that it is more than SS316LN across all interfaces. Hardness of D9 is measured around $390 \mathrm{VHN}$ and hardness of SS316 is measured around 260 VHN.

\section{Conclusions}

EM welding of tapered D9 tube to SS316 L (N) plug was successfully achieved using six turn tapered disc type EMW coil. Ten consecutive welded samples were generated by coil current ranging from 233 to $250 \mathrm{kA}$ at around $15.1 \mathrm{kHz}$ ringing frequency. All ten samples showed helium leak rate in the range of $10^{-9}$ $\mathrm{m} \cdot \mathrm{bar} \cdot \mathrm{L} / \mathrm{s}$ range using MSLD. Afterward all samples were subjected to X-ray tomography; there was no gross defect observed in tomography in the intended weld region. For interface study of welded region randomly selected sample was cut axially and circumferentially to be analysed using optical microscope. Prominent waviness was observed in around $7 \mathrm{~mm}$ length. Variation of microhardness at weld interface verifies the grain refinement due to severe plastic deformation at high strain rate during the EM welding process. 


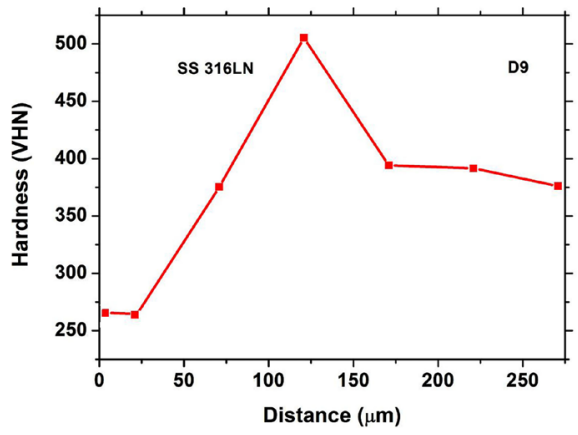

Figure 10. Hardness variation at weld interface of weld sample no. 7 .

Critical part in flared tube to flat welding is coil design which will also have tapered ID to accommodate D9 tube. In such case electrical insulation and mechanical strength become a limiting point for coil life. After 10 - 12 shots, EM coil needs to be refurbished. Furthermore, the influencing factors responsible for interface wave and bond formation, its mechanism, theories and physics involved can be studied by conducting thorough metallographic investigations in a separate study.

\section{Acknowledgements}

Authors are highly thankful to Shri R. K. Rajawat, Associate Director, Beam Technology Development Group, BARC for his continuous encouragement and guidance. Authors are also thankful to Dr. Arijit Laik and Mr. Srikanth V. for doing metallographic analysis and useful discussions.

\section{Conflicts of Interest}

The authors declare no conflicts of interest regarding the publication of this paper.

\section{References}

[1] Kochan, A. (2000) Magnetic Pulse Welding Shows Potential for Automotive Applications. Assembly Automation, 20, 129-132. https://doi.org/10.1108/01445150010321742

[2] Lampman, S., Ed. (1997) Weld Integrity and Performance: A Source Book Adapted from ASM International Handbooks, Conference Proceedings and Technical Books. ASM International, Ohio.

[3] Roeygens, L., De Waele, W. and Faes, K. (2017) Experimental Investigation of the Weldability of Tubular Dissimilar Materials Using the Electromagnetic Welding Process. International Journal Sustainable Construction \& Design, 8, 1-8. https://doi.org/10.21825/scad.v8i1.6810

[4] Lueg-Althoff, J., Bellmann, J., Gies, S., Schulze, S., Tekkaya, A.E. and Beyer, E. (2018) Influence of the Flyer Kinetics on Magnetic Pulse Welding of Tubes. Journal of Materials Processing Technology, 262, 189-203. https://doi.org/10.1016/j.jmatprotec.2018.06.005

[5] Cowan, G.R., Douglass, J.J. and Holtzman, A.H. (1964) Explosive Bonding. U.S. 
Patent No. 3,137,937. U.S. Patent and Trademark Office, Washington DC.

[6] Patra, S., Arora, K.S., Shome, M. and Bysakh, S. (2017) Interface Characteristics and Performance of Magnetic Pulse Welded Copper-Steel Tubes. Journal of Materials Processing Technology, 245, 278-286.

https://doi.org/10.1016/j.jmatprotec.2017.03.001

[7] Yu, H., Dang, H. and Qiu, Y. (2017) Interfacial Microstructure of Stainless Steel/Aluminum Alloy Tube Lap Joints Fabricated via Magnetic Pulse Welding, Journal of Materials Processing Technology, 250, 297-303. https://doi.org/10.1016/j.jmatprotec.2017.07.027

[8] Mannan, S.L., Chetal, S.C., Raj, B. and Bhoje, S.B. (2003) Selection of Materials for Prototype Fast Breeder Reactor. Transactions-Indian Institute of Metals, 56, 155-178. 